\title{
Editorial: Striving for Excellence in Pediatric Gastroenterology Care - A Continuous Effort
}

\author{
Anshu Srivastava ${ }^{1} \cdot$ Girish Gupte $^{2}$
}

Received: 3 August 2016 / Accepted: 3 August 2016 / Published online: 31 August 2016

(C) Dr. K C Chaudhuri Foundation 2016

"We are the world, we are the children. We are the ones who make a brighter day" Michael J. Jackson, Lionel B. Richie.

We as child specialists are faced everyday with the problems of pediatric patients, from neonatal period, infancy, childhood and adolescence until the transition of care to adult physicians or internists. Adding to the complexity of differences across this wide age spectrum is the rapid pace of advances in disease management across various pediatric subspecialities. We have an ongoing commitment to strive in order to improve pediatric care. Thus, there is a constant pressure to learn so that we can manage our children in accordance to the recent developments and guidelines in the field of pediatric care.

We have tried to make a small step in this direction by getting together this special symposium which provides a practical approach to some common problems in pediatric gastroenterology.

The first article is on "Recent advances in celiac disease" [1]. Celiac disease (CD) is a very common cause of chronic diarrhea and has a prevalence of $\sim 1 \%$ in the general population of North India [2]. The various presentations of celiac disease, be it classical, potential or refractory disease, are discussed in this article. It provides an in-depth discussion about the pathophysiology and mucosal immune response in

Anshu Srivastava

avanianshu@yahoo.com

1 Department of Pediatric Gastroenterology, Sanjay Gandhi Postgraduate Institute of Medical Sciences, Raebareli Road, Lucknow, Uttar Pradesh 226014, India

2 Liver Unit (Including Small Bowel Transplantation), Department of Gastroenterology and Nutrition, Birmingham Children's Hospital, Steelhouse Lane, Birmingham, UK
CD. It will help the readers in understanding the disease spectrum as well as the importance of making a correct diagnosis with complete work up.

Children with intestinal failure were traditionally managed with parenteral nutrition. However, intestinal transplantation has now become an accepted modality of treatment for these patients. The article on "Intestinal failure in children" provides information about the etiology and complexities in care of a child with intestinal failure [3]. It is also a valuable resource for recent information on intestinal transplantation. Valuable guidance regarding the nutritional and medical management of children with intestinal failure is also provided.

Pediatric gastroenterologists and pediatricians in India have witnessed an increase in the number of children being diagnosed with inflammatory bowel disease (IBD) in recent years [4]. The article on "Approach to a child with colitis" provides a road map to the paediatrician for the age-based causes, differentiation of infective from non-infective causes and evaluation of children with colitis [5]. The clinical presentation, diagnosis and recent advances in the multidisciplinary care of children with IBD, both ulcerative colitis and Crohn's disease are discussed at length.

Recurrent abdominal pain in children is a problem faced by all pediatricians and poses the dilemma of how to distinguish between those with organic etiology from those with functional pain abdomen. This article on "Approach to a child with functional abdominal pain" not only describes the various types of functional abdominal pains (FAP) but also provides guidance regarding differentiation of FAP from organic causes and planning of investigations [6]. It addresses the management issues including counselling and psychological care in detail.

Literature on pancreatic diseases in children is limited and an international group (INSPIRE) has been formed to 
standardize and improve the care of children with pancreatitis [7]. The article on "Pancreatitis in children" addresses the entire spectrum of pancreatitis i.e., acute pancreatitis (AP), acute recurrent pancreatitis (ARP) and chronic pancreatitis (CP) [8]. It will help the reader in differentiation of various forms of pancreatitis, finding the etiology and providing state of the art management. The article also provides Indian data regarding etiology in children which is valuable.

We thank the authors for making this effort and contributing towards this symposium and making the articles simple and practical. We hope that this will enrich and improve the care of our patients with gastrointestinal and pancreatic problems.

\section{Conflict of Interest None.}

Source of Funding None.

\section{References}

1. Murch S. Recent advances in celiac disease. Indian J Pediatr. 2016. doi:10.1007/s12098-016-2161-8.

2. Makharia GK, Verma AK, Amarchand R, et al. Prevalence of celiac disease in the northern part of India: a community based study. J Gastroenterol Hepatol. 2011;26:894-900.

3. Wong $\mathrm{T}$, Gupte $\mathrm{G}$. Intestinal failure in children. Indian $\mathrm{J}$ Pediatr. 2016. doi:10.1007/s12098-016-2219-7.

4. Sathiyasekaran M, Bavanandam S, Sankaranarayanan S, et al. A questionnaire survey of pediatric inflammatory bowel disease in India. Indian J Gastroenterol. 2014;33:543-9.

5. Palle SK, Prasad M, Kugathasan S. Approach to a child with colitis. Indian J Pediatr. 2016. doi:10.1007/s12098-016-2091-5.

6. Sood MR, Matta SR. Approach to a child with functional abdominal pain. Indian J Pediatr. 2016. doi:10.1007/s12098-016-2111-5.

7. Morinville VD, Husain SZ, Bai H, et al; INSPPIRE group. Definitions of pediatric pancreatitis and survey of present clinical practices. J Pediatr Gastroenterol Nutr. 2012;55:261-5.

8. Sathiyasekaran M, Biradar V, Ramaswamy G, et al. Pancreatitis in children. Indian J Pediatr. 2016. doi:10.1007/s12098-016-2115-1. 